\title{
Origen y primera elaboración de la viñeta 110 del Libro de la Salida al Día
}

\author{
Milagros ÁLVAREZ SOSA
}

\begin{abstract}
Nuestro interés por desarrollar un análisis iconográfico e iconológico de las ilustraciones del Libro de la Salida al Día, en el que la interpretación desplace a la mera descripción, nos ha llevado a plantear el estudio de una imagen concreta de este corpus, la viñeta 110, el llamado Campo de Juncos, Campo de Ofrendas o Campo de Hotep. Por esta razón, hemos previsto plantear, a través del análisis de esta ilustración, algunas cuestiones sobre el origen, evolución y transmisión de este corpus. Esta comunicación se centrará en uno de los modelos que hemos establecido para identificar la iconografía de la imagen, nuestro "tipo A". Es el más antiguo, pues se documenta desde comienzos de la dinastía XVIII, en paralelo a los primeros ejemplares ilustrados de esta composición funeraria. Se ha investigado el origen y formación de la viñeta a través de sus antecedentes en los Textos de los ataúdes. El examen de su transmisión posterior nos ha permitido ver cómo se mantiene o transforma cuando cambia de soporte, de los ataúdes a las paredes de las tumbas y a los papiros. La comparación entre los ejemplares de la Dinastía XVIII nos ha conducido a establecer que su representación más antigua documentada se encuentra en la TT 353.
\end{abstract}

\section{Origin and first elaboration of the vignette 110 of the Book of Going Forth by Day}

Our interest in developing an iconographic and iconological analysis of the pictures of the Book of Going Forth by Day in which interpretation takes the place of mere description, has led us to propose the study of a specific image within this corpus, vignette 110, known as Field of Reeds, Field of Offerings or Field of Hotep. For this reason we have formulated, through the study of this illustration, some questions about the origin, evolution and transmission of this corpus. This paper will focus on one of the models that we have established to identify the iconography of the image, our "type A". It is the oldest, and so it is dated to the beginning of the $18^{\text {th }}$ Dynasty, in parallel with the first illustrated documents of this funerary composition. The origin and formation of the vignette has been researched through its antecedents in the Coffin Texts. The analysis of its later transmission has enabled us to see how this is preserved or tranformed when support alters, from coffins to the walls of tombs and to papyri. Comparison between the specimens of the $18^{\text {th }}$ Dynasty has led us to establish that its oldest representation is found in the TT 353.

KeY words: $18^{\text {th }}$ Dynasty, Coffin Texts, Book of Going Forth by Day, el-Bersha, Thebes, Senenmut

$\mathrm{M}$ ostrar el valor de la imagen como un documento que nos puede permitir reconstruir aspectos de la sociedad, mentalidad y religiosidad egipcia fue el objetivo que nos llevó a centrarnos en el estudio de viñeta 110 del Libro de la Salida al Día (= LdSD). Ésta representa un espacio del Más Allá egipcio denominado Campo de Juncos, Campo de Ofrendas o Campo de Hotep. En la literatura divulgativa sobre la religión egipcia, se ha calificado en ocasiones como el "lugar de morada del difunto al que accede tras obtener el veredicto del Tribunal Divino",

* Esta investigación ha sido posible gracias a la ayuda inestimable de mi director de tesis el Dr. Miguel Ángel Molinero Polo, al que deseo expresar mi gratitud.

Fecha de recepción: 12 de junio de 2008

Fecha de admisión: 15 de julio de 2008

http://doi.org/10.25145/j.TdE.2009.05.01.04 
o como "Campos Elíseos" y "Paraíso Egipcio", denominaciones que son fruto de una comparación errónea con la concepción de la otra vida griega, cristiana y de otras creencias.

A partir de un análisis iconográfico, en este trabajo presentaremos un estudio de esta viñeta centrándonos en su posible lugar de aparición y su formación durante la Dinastía XVIII.

\section{REINO ANTIGUO}

Primeras Referencias literarias a los CaMpos CELESTES

Las primeras referencias a estos Campos las hallamos en los Textos de las Pirámides (= PT) del Reino Antiguo. Estas regiones reciben dos denominaciones diferentes: 看

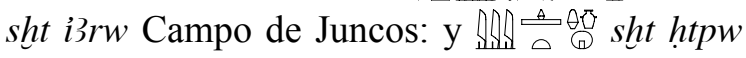
Campo de Ofrendas ${ }^{1}$.

Desde un punto de vista general, las nociones míticas en que se mencionan aluden a unos campos inundados de agua, con estanques, tierra y canales por los que el difunto se desplaza en barca; los dioses y el rey acuden a ellos a purificarse. Junto a esta imagen compartida por ambos, también podemos identificar pequeñas diferencias entre ellos. Los textos dejan claro que el Campo de Juncos permite el renacimiento y se entiende, así, como una región de paso $^{2}$; por el contrario, el Campo de Ofrendas se define como un lugar benéfico para el rey, donde encuentra comida y agua y donde están también su $k 3$ y los $k 3 w$ de los dioses. Todos ellos necesitan ser alimentados y es en este espacio donde esto tiene lugar:

Puedan ellos permitirme comer de los campos y beber de los estanques que están dentro del Campo de Ofrendas. (PT 1200 a-c) $)^{3}$

En todo el conjunto de las composiciones funerarias del Reino Antiguo, sólo conocemos una referencia al hecho de poder cultivar y cosechar en estas regiones ${ }^{4}$. Esto es aún más sorprendente si tenemos en cuenta la importancia que esta actividad tendrá en la concepción de estos lugares en períodos posteriores ${ }^{5}$.

\section{REINO MEDIO}

\section{El plano del Campo en los ataúdes de EL-Bersha}

La primera representación iconográfica de estos campos del Más Allá la encontramos en diez ataúdes ${ }^{6}$ de el-Bersha, necrópolis de Hermópolis, cuyos propietarios fueron miembros de la familia gobernante y altos funcionarios del Distrito XV del Alto Egipto (Distrito de la Liebre) ${ }^{7}$. Se trata de un plano $^{8}$ que se sitúa en una de las paredes laterales del ataúd y que es el elemento central de una secuencia de cuatro textos que aparece

1. La grafía de ambas palabras varía alternando indistintamente sus determinativos. sht i3rw puede aparecer con diferentes signos vegetales y el sht htpw con los elementos que componen una ofrenda.

2. Ver: PT 749c.

3. Trad.: Faulkner, 1969: 191.

4. PT 873d-874a, Versión de la pirámide de Merenre I.

5. Hays (2004) ha realizado un estudio basándose en las referencias literarias de los Campos de Juncos en los PT y la transmisión de éstas a los CT. Se ha centrado en el cambio de significado de esta región del Más Allá de un periodo a otro y en la continuidad y discontinuidad en el contexto en el que apareció el término de Campo de Juncos.

6. B6C, B9C, B5C, B15C, B17C, B1C, B2P, B1L, B3L y B4L.

7. Willems, 1988: 71.

8. En la organización de los Textos de los Ataúdes publicada por Buck, 1935-1961 ha recibido el número 466. 


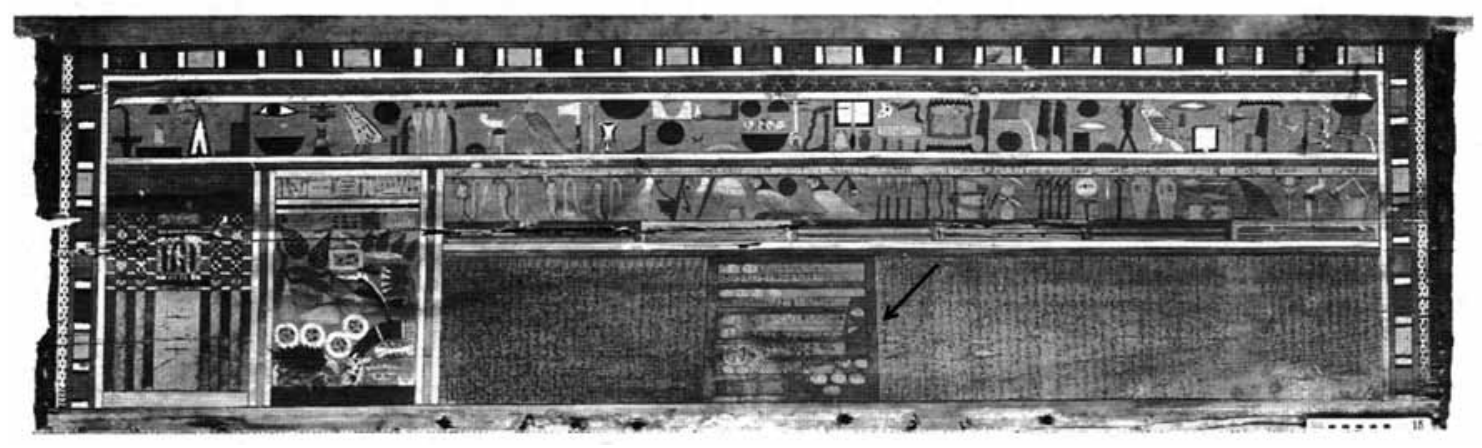

Figura 1. Localización del Plano de Hotep en el lado frontal del ataúd B3L (Dinastía XII)

en todos los documentos siempre en el mismo orden, del 464 al 467. No lo encontramos en ninguna otra necrópolis, aunque desde el más antiguo de los ataúdes hasta el más reciente han pasado ciento veinte años; éstos podrían considerarse tiempo suficiente para que se hubiera transmitido hacia otras regiones donde los ataúdes y otros elementos del ajuar de las elites locales también incluían textos ${ }^{9}$. Salvo que se diera la circunstancia de que existiera en otros lugares y no se haya conservado, tendríamos que concluir que el plano se creó en Hermópolis y fue utilizado sólo para su grupo dirigente, que lo reservó para sus ataúdes; tampoco en elBersha se ha documentado en ningún otro objeto del ajuar.

Hay que destacar que no se encuentran indicaciones de que la jerarquía social de sus propietarios esté reflejada en una variación tipológica de la imagen, puesto que el plano es el mismo tanto para los gobernadores como para los altos funcionarios del distrito.

En los Textos de los ataúdes (= CT), el plano puede recibir la designación de Campo de Ofrendas o Campos de Hotep All sht htp.
El determinativo es el que nos induce a comprender $h t p$ en este segundo como el nombre de una divinidad.

Todos responden a un mismo diseño interior. La imagen la encontramos ubicada en la pared frontal del ataúd. Para la descripción de ésta vamos a tomar B3L como ejemplo (fig. 1). En el registro superior encontramos un texto jeroglífico con la fórmula de ofrendas tradicional a Osiris o a Anubis y en el que figura el nombre del propietario del ataúd como beneficiario. La banda central contiene representaciones de objetos de uso diario y ceremonial pero con un significado simbólico para el Más Allá. El registro inferior es el de más altura y está dividido en tres segmentos, los cuales contienen la representación de una falsa puerta, una mesa de ofrendas y, en el más extenso, una serie de columnas verticales de textos en escritura cursiva, a los que se incorpora el plano del Campo de Hotep ${ }^{10}$.

La presentación de esta región en los CT se aleja de la visión vaga de los PT, dándonos una descripción física más detallada tanto de ella como de los trabajos agrícolas que se realizan en sus tierras:

9. Como podemos ver en los ataúdes conservados de las necrópolis de Beni-Hasan, Meir, Saqqara o Tebas. Ver: Willems, 1988.

10. Ver: Lesko, 1971/1972. 

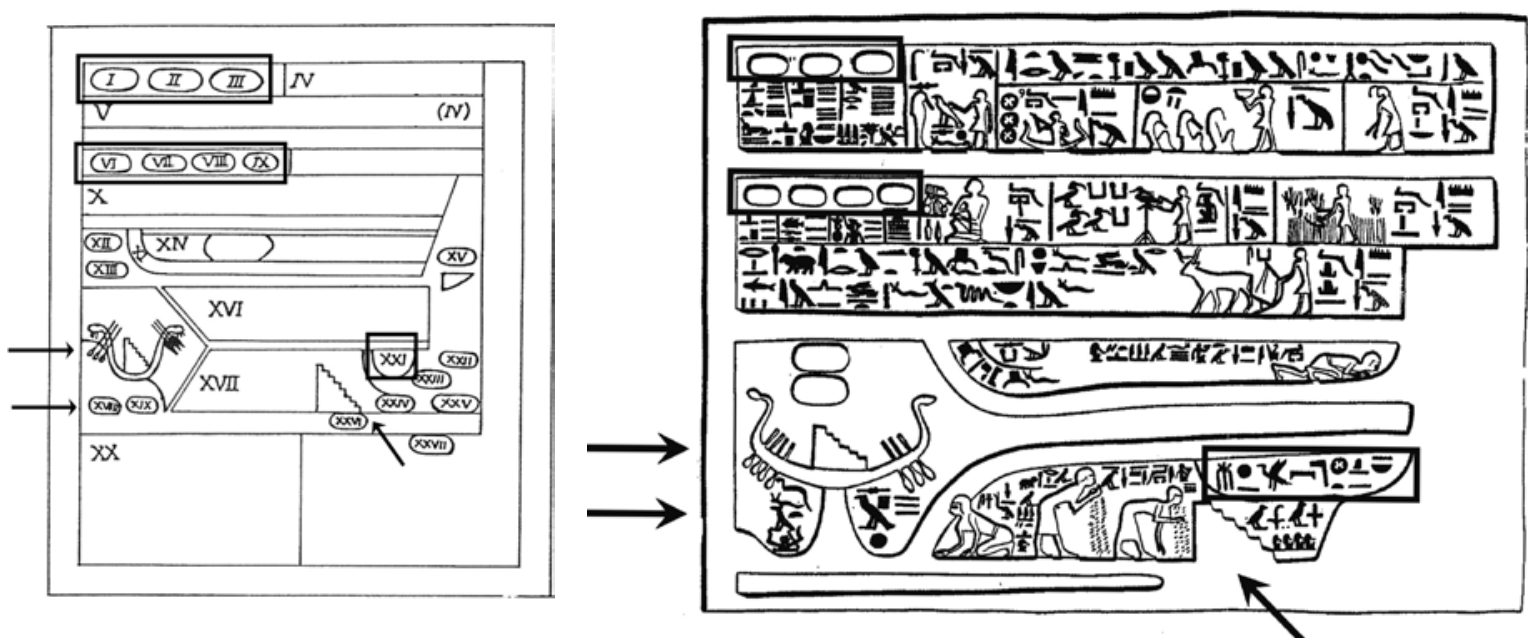

Figura 2. Comparación del Plano de Hotep de un ataúd de el-Bersha, B5C (Reino Medio) donde aparecen señalados los primeros elementos iconográficos que definen el Campo y la viñeta en la Tumba de Senenmut

(Reino Nuevo)

Yo conozco ese Campo de Juncos que pertenece a Re, la pared de cuyo recinto es de hierro; la altura de su cebada es de cuatro codos, su espiga es de un codo, su tallo es de tres codos; su espelta es de siete codos, su espiga es de dos codos, su tallo es de cinco codos. Los habitantes del horizonte son los que cosechan en una longitud de nueve codos en presencia de las Almas de los Orientales, que son Horakhty, el... ternero (?) y la Estrella de la Mañana. (CT 159, II 368c-372a) ${ }^{11}$

Los únicos elementos iconográficos (figura 2a) que presenta el plano son: los canales, que se emplean para dividirlo; los óvalos que se utilizan para señalar sus distintas regiones incluyendo textos descriptivos o palabras; una esca[52 ] lera y una barca, representaciones figurativas de la capacidad de desplazamiento del difunto, la primera con un sentido más literal, para moverse dentro del Campo y, la segunda, como símbolo del acceso al Más Allá. Como veremos más adelante, todos ellos se incorporarán posteriormente a la viñeta 110 del LdSD, aunque ésta se va a caracterizar por una mayor riqueza iconográfica.

Los textos incluidos en el plano parecen evocar dos tipos de lugares diferentes que encuentran en el Valle del Nilo su referente indudable: el paisaje natural del río con sus marismas y cañaverales y el que manifiesta las transformaciones del ser humano (canales, campos labrados...). Sólo un texto del interior del plano alude a la hacienda del dios en la que el difunto puede arar y segar, evidentemente para la obtención de su alimento. Se lee:

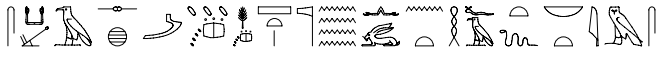

$$
\begin{aligned}
& \text { sk3 sh it bd(t) št ntr ; } n \text { wnt hf } 3 t \text { nbt im=s }
\end{aligned}
$$

Arar y segar cebada y escanda de la hacienda del dios. No hay ninguna serpiente en ella.

Por tanto, podríamos afirmar que el texto XIV es el que pudo haber servido de base para la idea

11. Trad.: Faulkner, 1978: 138. Se trata de un texto significativo ya que es la primera referencia que describe con detalle el Campo de Juncos y presenta las características que se plasmarán en la viñeta 110 del LdSD. Esta descripción se corresponde con la que aparece en la recitación 109 de este corpus que a su vez se repite en la 149. 
de incluir una escena de trabajos agrícolas en las viñetas posteriores del $\mathrm{LdSD}^{12}$.

La imagen del Campo en los CT parece tener una doble vertiente: su designación como Campo de Ofrendas sugiere un significado de espacio para el aprovisionamiento del difunto. Si atendemos a los diferentes textos y elementos decorativos del ataúd, vemos que todos tienen que ver con la alimentación y el evitar las carencias en el Más Allá, es decir, con el ritual funerario de ofrenda ${ }^{13}$. Por otro lado, el plano parece cumplir la función de guiar al difunto en su camino por el Más Allá y de resguardarlo de cualquier peligro en su nuevo y divino entorno ${ }^{14}$

\section{DINASTÍA XVIII}

\section{LA VIÑETA 110 DEL LDSD}

De mediados de la Dinastía XII hasta la XVIII no documentamos la imagen en ninguna necrópolis. Transcurren algo menos de cuatrocientos años entre su desaparición en el Reino Medio y su resurgimiento en el Reino Nuevo, en la capital de la nueva dinastía, Tebas.

Resulta interesante destacar que cuando reaparece la imagen del Campo de Juncos o Campo de Ofrendas como viñeta 110 del LdSD no lo hace en los ataúdes del Reino Nuevo, sino en tumbas y papiros. Aunque no contamos con ningún testimonio intermedio, los modelos de esta región del Más Allá debieron de conservarse en la biblioteca de algún templo, seguramente en el de Hermópolis. No podemos saber por cuánto tiempo. También es posible que en determinado momento, éstos pasaran a otras necrópolis de Egipto y no se hayan conservado. Respecto al contexto en que esta imagen fue exportada de su ciudad de origen, cabrían dos posibilidades: a) aparece en Tebas durante la Dinastía XVIII traída directamente desde Hermópolis; b) llega a Tebas durante la Dinastía XII o después pero ésta no fue representada hasta la construcción de la tumba de Senenmut. También podríamos plantearnos que antes pudo haber estado en otros soportes y que no se hayan conservado. La falta de fuentes sólo nos permite hipotetizar.

El análisis que he realizado para mi tesis de unos 130 ejemplares de viñeta sobre papiro ${ }^{15}$, datados desde la Dinastía XVIII hasta los Periodos Tardío y Ptolemaico, ha permitido establecer tipologías de modelos a las que hemos llegado mediante: a) reconocimiento del marco estructural creado con líneas de agua dentro de las cuales las escenas son representadas; b) identificación de cada una de las escenas dentro del marco: los personajes que la constituyen y su gestualidad; reducimos cada escena a un nombre identificativo; c) dibujo de un "esquema" de cada viñeta, en el cual ambos (a y b) están presentes.

12. Este texto estará incluido entre las leyendas que compondrán la viñeta 110 en el Reino Nuevo.

13. Los primeros textos e imágenes que se crearon para asegurar una buena vida después de la muerte se ocupaban de aprovisionar al difunto con todo lo necesario. Se trataba de estelas para la fachada de la tumba en las que se representaba al muerto con su nombre y títulos sentado sobre una mesa de ofrendas y la lista de los bienes materiales que se suministrarían a la tumba. Ver: Hartwig, 2004: 86-97.

14. Algunos de los textos que rodean al difunto en el ataúd parecen estar encaminados a dar información sobre las regiones del Más Allá con el objetivo de prevenirlo de peligros y que pueda realizar su viaje satisfactoriamente. Destaca en especial el Libro de los Dos Caminos, dibujado en el fondo del ataúd y definido como la primera cosmografía egipcia. Ver: Lesko, 1977.

15. Varios son los museos e instituciones científicas que nos han proporcionado material para este estudio: Totenbuchprojekt (Universidad de Bonn), Museo de Turín, Museo de Leiden, Museo Británico, Museo de Viena y Museo Metropolitano de Arte (Nueva York). 


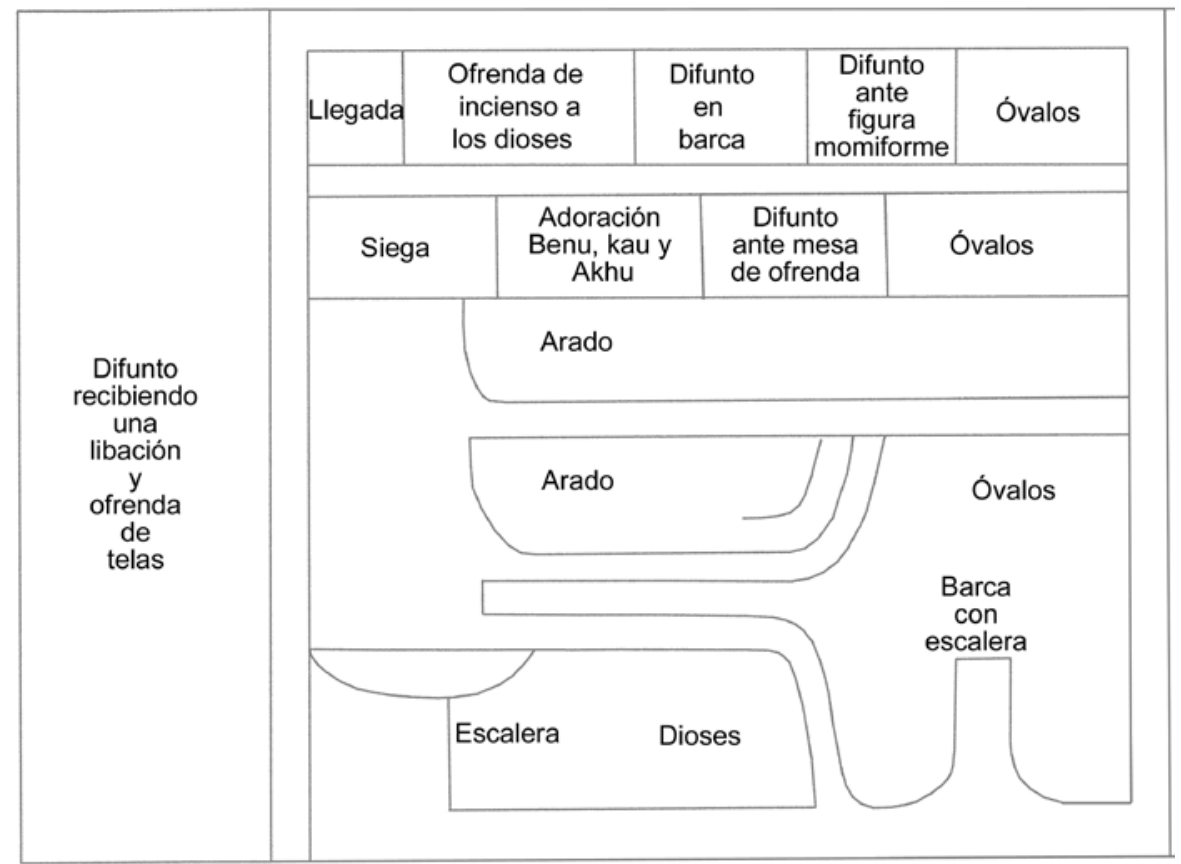

Figura 3. Esquema de la viñeta tipo A

El orden de elementos que compone cada "tipo" sigue un esquema fijo que se repite. De los grupos que hemos estudiado, el tipo A, el más antiguo, coincide con el periodo de aparición del Libro de la Salida al Día sobre papiro. A este tipo nos vamos a referir a lo largo de este estudio $^{16}$.

Hemos documentado sólo nueve viñetas tipo A durante la Dinastía XVIII, de las que cuatro están sobre papiro y cinco en tumbas ${ }^{17}$. El hecho de que sea escaso el número de ejemplares permite papiro de Nebseni, que es menfita. Además, es el único de ellos que está dibujado con trazos negros y sin colorear las figuras ${ }^{18}$. Esta circunstancia hace plantearse ciertas dudas respecto al origen y transmisión del modelo, cuestión que intentaremos resolver a través de este estudio.

La adscripción de todas estas viñetas a un solo tipo se ha hecho en base a sus características iconográficas. Las dos más significativas son el orden de escenas de la viñeta, que presenta un esquema fijo e inalterable (figura 3) y la incorporación de una escena de purificación que será propia de este tipo A y que desaparece con éste no llegando a formar parte de la versión posterior

16. Hasta el momento es el único que hemos documentado para la Dinastía XVIII.

17. Ejemplares sobre papiro: Iuia (Cairo CG 51189) (Munro, 1994), Nebseni (BM 9900) (Lapp, 2003), Userhat (BM 10009), Neferubenef (Louvre N. 3092) (Ratié, 1968); ver: Munro, 1987: 274-291. Ejemplares sobre tumbas en: TT 353, TT B2, TT C4, TT 57, TT 120. Aunque desconocemos la representación de la viñeta en la TT B2 y TT 120 las incluimos ya que aparecen citadas en el Porter y Moss, 1985: 234 y 455 y en Saleh, 1975: 59.

18. Niwinski señala dos escuelas de fábrica de papiros para el periodo más temprano en el que aparece el LdSD. Una de ellas, según el autor, usaría una sola tinta por lo que las figuras y el borde del marco de los papiros estarían dibujados en líneas negras y sin ningún color. Ver: Niwinski, 1989: 229. 
del Libro de la Salida al Día. Sólo la volvemos a encontrar en algunos papiros que recuperan el modelo durante la Dinastía XXI ${ }^{19}$.

La viñeta tipo A está dividida en tres registros (figura 4). En el primero aparece el difunto solo en una escena que hemos interpretado como "llegada al Campo de Juncos", y después haciendo una ofrenda de incienso a los dioses ${ }^{20}$. La escena central es la del muerto en la barca en actitud de remar. A ésta le sigue otra en la que el propietario se halla ante una figura momiforme de pie. Se completa con tres óvalos que pueden tener incluido texto.

En el segundo registro encontramos cuatro escenas: la siega del cereal, la adoración al ave Benu, el difunto ante una mesa de ofrendas y tres óvalos.
El tercer registro se subdivide en dos partes. En la superior se hallan dos escenas de arado con el propietario como protagonista. En la inferior, aparece la representación de una barca con escalera, sobre la que se dibujan dos óvalos. En una isla formada por los canales se sitúan cuatro dioses junto a una escalera, además de otra isla con un texto que la identifica como el lugar de nacimiento de las divinidades.

La segunda característica que se ha de destacar del tipo A es la incorporación de la imagen del difunto recibiendo una libación y una ofrenda de telas, escena que tiene sus paralelos en el programa decorativo de grandes construcciones del Reino Nuevo. Podemos establecer así una correspondencia con las imágenes de los reyes o de personajes de la clase alta que en sus tumbas

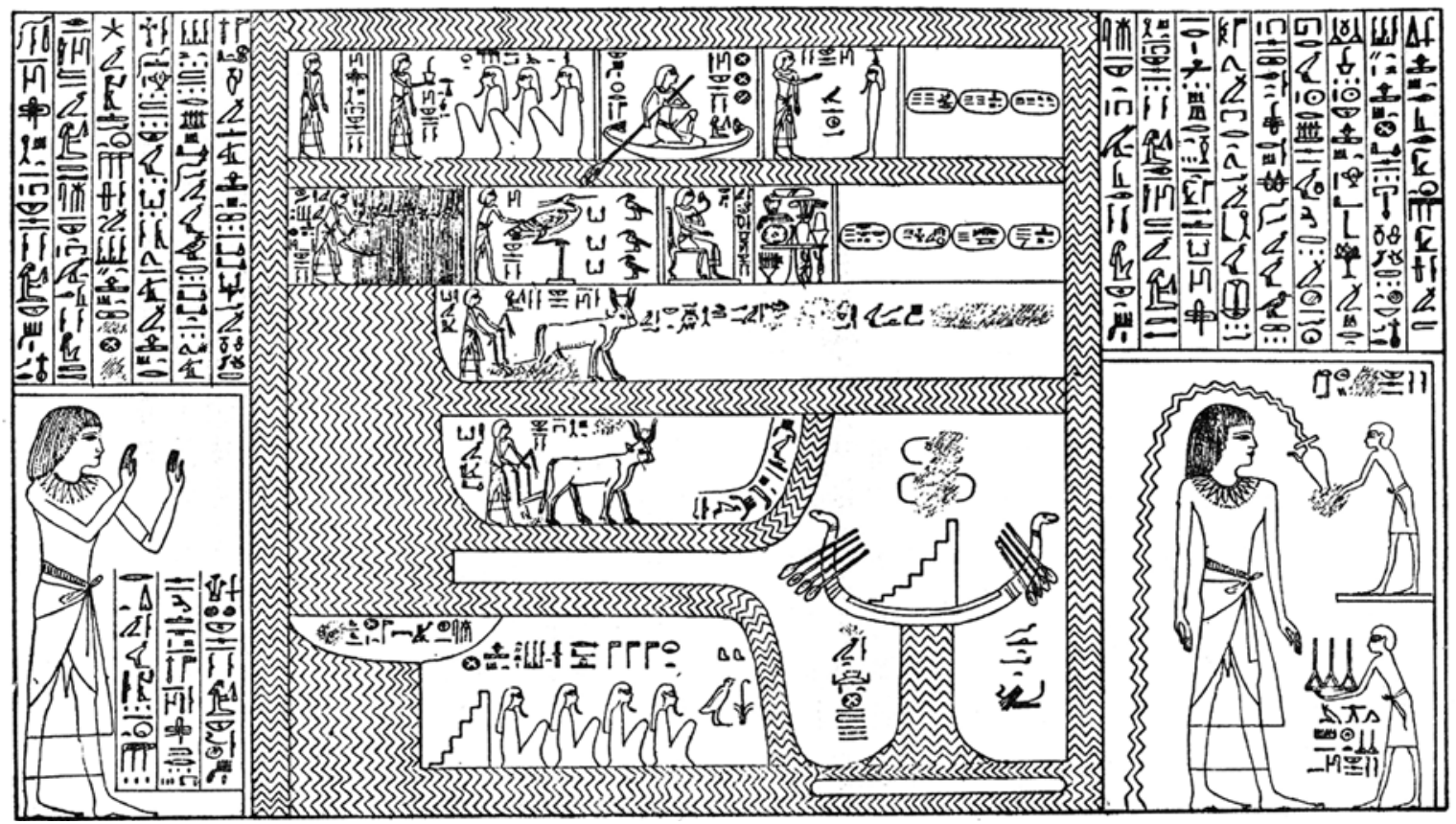

Figura 4. Viñeta tipo A. Papiro de Nebseni (Dinastía XVIII)

19. Por ejemplo, el papiro de Gatseshen (Cairo J.E. 95838 = S.R.IV 936) (Lucarelli, 2006) y en el de Panensetawy (BM 10064) (Munro, 2001).Ver: Álvarez Sosa, en prensa.

20. Tenemos la excepción del papiro de Iuia (Cairo CG51189) en el que el difunto aparece acompañado de su mujer en una escena de recogida de lino. Ver: Munro, 1994; Álvarez Sosa, en prensa. 
reciben ofrendas y libaciones por parte de individuos que se representan a una escala más reducida o de dioses recibiendo ofrendas por parte del rey en los templos. Las ropas que llevan los oferentes (dobles faldellines, uno más corto y otro más largo) también documentan la moda del Reino Nuevo.

Esto nos lleva a la conclusión de que la imagen del Campo en las viñetas tipo A se compuso mediante la transformación del plano 466 de los CT de el-Bersha del Reino Medio y la yuxtaposición a ésta de una escena de purificación y ofrendas de telas que debe de ser de reciente creación ya que se documenta a partir de la Dinastía XVIII.

\section{La tumba de Senenmut}

De los nueves ejemplares tipo $\mathrm{A}^{21}$, la representación más antigua del Campo de Juncos está vinculada a un alto funcionario de las reina Hatshepsut, Senenmut. Su tumba, la TT 353, se ubica en Deir el-Bahari ${ }^{22}$ y es contemporánea al surgimiento del LdSD ${ }^{23}$.

Esta tumba destaca por un aspecto muy singular como es el de estar construida en el entorno de la zona sagrada del templo funerario de Hatshepsut. La entrada queda fuera del recinto, pero la cámara mortuoria está situada bajo el templo de la reina.
La tumba se compone de tres cámaras. Solo la primera (la Cámara A) está decorada, las otras dos (la Cámara A y B) están inacabadas. La decoración presenta el más antiguo techo con motivos astronómicos conservado en una sepultura de la necrópolis tebana ${ }^{24}$.

La imagen del Campo de Juncos se encuentra en la denominada Cámara A, rodeada de otras recitaciones de este libro funerario, algunas de ellas ilustradas con viñetas ${ }^{25}$. El conjunto iconográfico y textual está relacionado con la geografía del Más Allá y el viaje del difunto.

El tamaño de la viñeta de la tumba de Senenmut es bastante reducido si lo comparamos con las escenas que aparecen en otras tumbas del Reino Nuevo, en las que los personajes suelen representarse a gran escala. Atendiendo a las dimensiones del Campo de Juncos, es interesante resaltar que los dibujantes no aprovechan las dimensiones de la pared. La viñeta parece conservar la proporción de los papiros ${ }^{26}$, lo que resulta curioso si tenemos en cuenta la difícil ejecución de las figuras a un tamaño tan reducido. En este sentido, también podría argumentarse que su reducción atendiera al espacio disponible ya que el resto de la pared está plenamente decorada con textos, pero es poco probable.

La viñeta 110 está realizada en relieve y carece de color. Se divide en tres registros separados

21. Tres están datados en tiempos de Amenhotep III (pIuia, TT57, TT120), dos de Thutmosis IV (pNebseni y pNeferubenef), uno de Thutmosis III (TT B2) y otro con una cronología vaga que oscila entre el reinado de Hatshepsut y Amenhotep III (pUserhat). Sólo Senenmut podemos datarlo con seguridad durante el reinado de Hatshepsut.

22. Se le asignan dos tumbas: la TT 71 y TT 353. El LdSD lo encontramos presente en ambas tumbas así como en diferentes objetos de su ajuar funerario (sarcófago, sudarios). La publicación de ambas tumbas en Dorman, 1991.

23. Anteriormente hay recitaciones de esta composición redactadas para la familia real tebana precedente. Hasta Hatshepsut el corpus se va aumentando con textos que eran copiados sobre el ataúd antropoide o sobre sudarios. Es durante el gobierno de esta reina cuando el uso de esta obra se extiende a los altos funcionarios de la corte y sus parientes, al tiempo que se cambia el soporte, empezándose a utilizar preferentemente el papiro.

24. Para un estudio detallado del techo ver: Pogo, 1930: 301-325 (la descripción más antigua); también Neugebauer y Parker, 1960-1969: III, 10-12; Etz, 1997: 143-61. Las más recientes: Shaltout y Belmonte, 2007; Lull y Belmonte, 2006.

25. Recitaciones: 136A, 136B, 137B, 144, 145, 146W, 148, 149, 150.

26. Por las medidas dadas por Dorman (1991) la altura de la viñeta viene a ser de unos $40 \mathrm{~cm}$ la medida que puede alcanzar el alto de un papiro según apunta Cerný, 1952: 6. 
por las habituales bandas, aquí sin decoración y que interpretamos como canales. A su vez, cada registro está dividido por líneas incisas finas que separan escenas y textos. A la izquierda, y en yuxtaposición, encontramos la escena de purificación y ofrenda de telas al difunto.

Un estudio comparativo entre la representación de la tumba y el plano de la recitación 466 de el-Bersha (figura 2), nos ha permitido ver que no sólo ambos tienen los mismos textos sino que la disposición de sus elementos iconográficos también es idéntica, de tal manera que del grupo de viñetas que se integra dentro de la tipología A, la de Senenmut parece casi una réplica exacta de la del Reino Medio a la que le hubieran añadido varias figuras.

El hecho de que no haya otra viñeta en tumba o papiro que tenga tanto parecido con el plano del Reino Medio, como lo tiene Senenmut, nos ha permitido pensar que los papiros tipo Ade este periodo pudieron tomar para su confección iconográfica la imagen que se creó para esta tumba. Esta hipótesis la apoyamos en los siguientes argumentos:

1) La localización de los óvalos y los textos dentro de la viñeta son idénticos al ataúd en las tres viñetas de tumbas, lo que permite inmediatamente vincularlas con los CT. En los papiros el esquema es idéntico, pero invertido izquierda-derecha. Los ejemplares posteriores del Libro de la Salida al Día alterarán de manera muy diversa la ubicación de los óvalos y textos dentro de la viñeta.
2) Aunque Senenmut sólo presenta una escena de arado con respecto a las dos que aparecen en las viñetas sobre papiro, aquélla pone la base textual para la incorporación de la segun$\mathrm{da}$, pues aparece la palabra $s k 3$ en un extremo de una de las dos islas del tercer registro. De esta manera, en los ejemplares posteriores nos encontramos con el difunto arando dos campos. Éstos podrían ponerse en relación con la alusión dada en la viñeta de Senenmut a los shty htp, los dos Campos de Hotep.

La conexión de los CT con esta tumba no se limita a la imagen. El texto de la recitación 110, ilustrado por la viñeta, es una derivación directa de los textos 464, 465 y parte del 467 de los CT que se copiaban en torno al Plano de Hotep en los ataúdes.

Es interesante destacar que hasta la redacción del LdSD, la designación como Campo de Hotep de esta región del Más Allá sólo se conocía por recitaciones aparecidas en ataúdes de el-Bersha. Este aspecto resulta significativo en el estudio del proceso de transmisión de la recitación 110 de los CT a la tumba de Senenmut ${ }^{27}$. La alusión al Campo de Hotep todavía se conserva en la recitación que acompaña a la viñeta y dentro de ella (ver tercer registro), designación que se pierde en la inclusión de esta recitación sobre papiro ${ }^{28}$.

También el estudio de la grafía parece ayudarnos en nuestros planteamientos. En los textos a partir del Reino Nuevo vamos a encontrar el nombre determinado en la mayoría de los casos por el signo $\otimes^{29}$. En el caso de los papiros tipo A,

27. Un estudio de las variaciones textuales en Dorman, 1991.

28. En el LdSD hay una preferencia por denominar esta región como Campo de Juncos o Campo de Ofrendas. Sin embargo, en la tumba de Senenmut la palabra Campo de Juncos únicamente aparece sobre la escena de purificación, que es una escena, con su texto, incorporados a la viñeta en el Reino Nuevo.

29. El logograma niwt ha sido habitualmente traducido por "villa", "ciudad" Wb. II 210, 7 - 212, 4; Faulkner, $1988: 125$. Ver: Moreno García, 1999:118. El jeroglífico ha sido interpretado como el plano de una villa con dos rutas en su interior. El signo funciona también como determinativo de ciertos elementos del paisaje, de nombres de regiones o de topónimos diversos, que es la función que tiene aquí. En la viñeta del Campo de Juncos principalmente a partir del Periodo Tardío, sobre la representación del difunto remando en la barca o frente a ella, pueden aparecer tres signos niwt que hemos interpretado como los lugares hacia los que éste rema. 
acordes con su herencia de los ataúdes del Reino Medio, se conserva la designación Afh sht htp, Campo de Hotep.

\section{LA TRANSMISIÓN DE LA VIÑETA}

Desde el Reino Antiguo hasta el Reino Nuevo, las vagas ideas iniciales sobre los campos del Más Allá evolucionan hasta ofrecernos el plano de un espacio más concreto en la representación de los ataúdes de el-Bersha. Las referencias literarias al Campo de Juncos en los tres corpora funerarios (PT, CT, LdSD) demuestran las relaciones intertextuales entre ellos además de cambios de significado ${ }^{30}$. La definición de esta región durante el Reino Antiguo como lugar de purificación y de paso perdió significado en el Reino Medio, que la consideró más como un lugar de destino y aprovisionamiento, así como de objeto de conocimiento.

La viñeta 110 es el resultado del desarrollo de una imagen en dos momentos específicos: el Periodo Heracleopolitano y las primeras décadas de la dinastía XVIII, seguramente durante el reinado de Hatshepsut, coincidiendo con el momento de creación del LdSD sobre papiro.

Un análisis iconográfico de esta primera tipología de viñeta lo hemos realizado centrándonos en las diferencias y similitudes del plano de Hotep sobre los ataúdes, el modelo de Senenmut y la imagen en papiros y tumbas. Esto nos ha permitido plantear un estudio sobre su origen y transmisión con el objetivo de reconstruir el arquetipo, es decir, el tipo de viñeta que más se acerca a la original (figura 5).

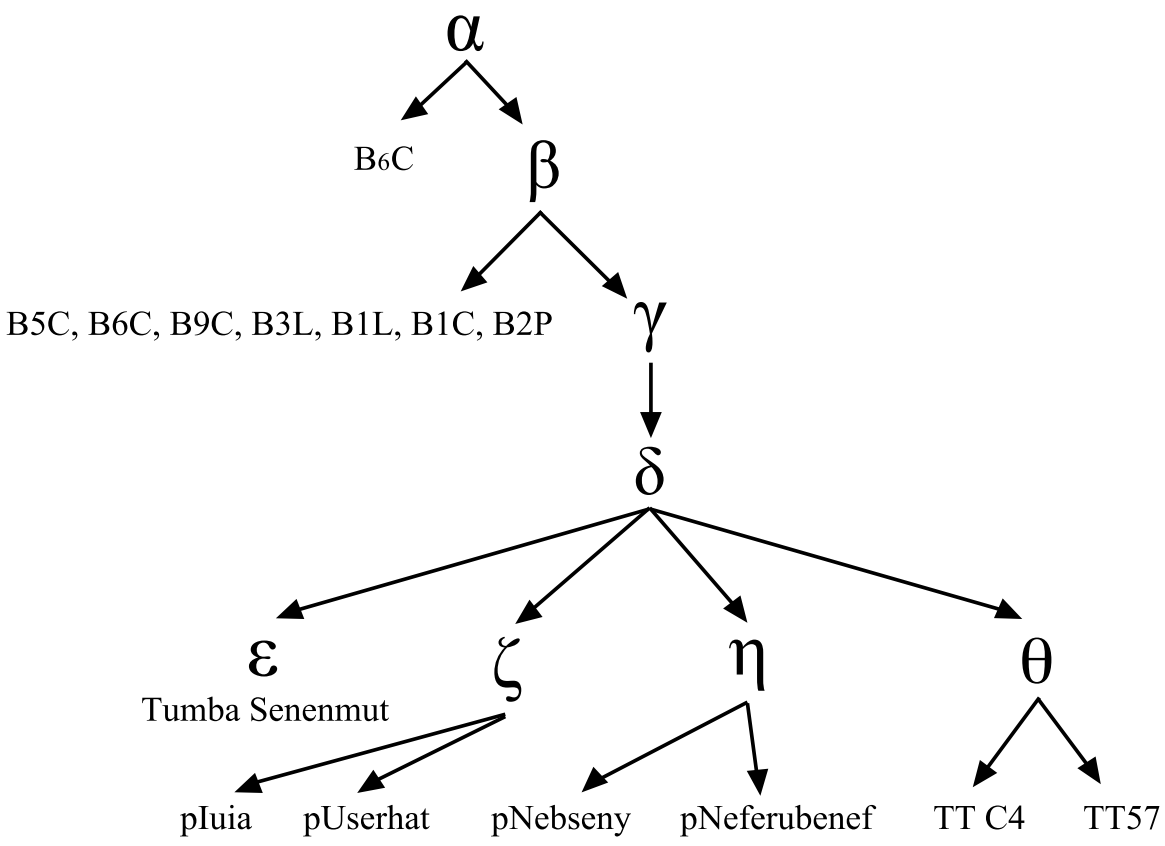

Figura 5. Stemma de transmisión

30. Hays (2004) defiende que en la transmisión de los textos no podemos hablar de una transmisión mecánica ni de una perpetuación de las viejas ideas sino de una vitalidad del discurso que no sólo permitió que determinadas ideas se transmitieran o que textos fueran sometidos a cambios sino que además se crearan otras. 
La que probablemente sea la versión más antigua del Plano de Hotep se encuentra en el ataúd B6C de el-Bersha, del reinado de Amenemhat I (figura 6). Éste, no sólo se data como el más antiguo sino que también la versión de su plano se diferencia del resto de los representados en la necrópolis. El Campo se distingue por estar compuesto sólo por textos y sin líneas que lo dividan.

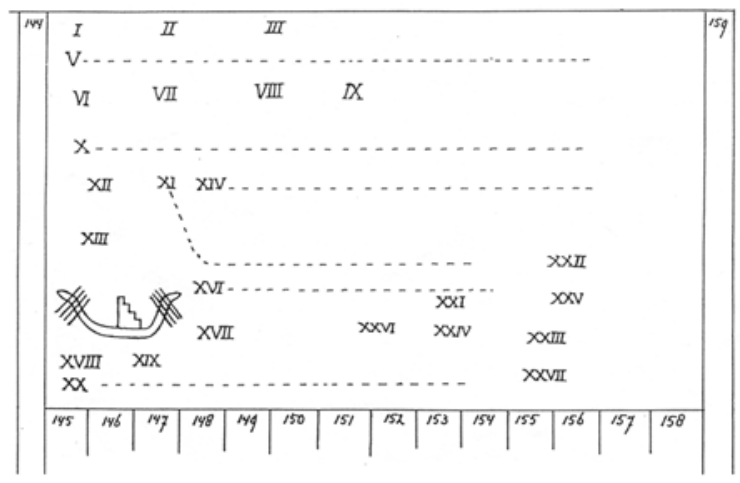

Figura 6. Plano del Ataúd B6C (Dinastía XII)

Los modelos posteriores, representados en los otros ataúdes, son más parecidos entre ellos ${ }^{31}$. Un estudio de las diferencias de éstos con el plano más antiguo nos ha permitido ver que la disposición de los textos de $\mathrm{B} 6 \mathrm{C}$ se corresponde milimétricamente con la localización que tienen en el plano del resto de ataúdes, además de la presencia de la barca en la parte inferior. Esto nos lleva a considerar que de una misma copiamaestra $(\alpha)$ deriva el tipo de plano de B6C y otra copia (ß) que sería la que serviría de modelo para el resto de planos de Hotep representados en el-Bersha.

El plano no se documenta como un elemento excepcional, ya que el número de gobernadores y funcionarios que lo incluyen dentro de la deco- ración de sus ataúdes no es alto si atendemos al número total de los procedentes de este lugar ${ }^{32}$.

También hay que resaltar el hecho de que no se produjera una propagación de este modelo concreto fuera del Nomo de la Liebre. Tal vez el celo de los sacerdotes en su custodia explica que no se difundiera por otras necrópolis, lo que sí va a suceder durante la dinastía XVIII cuando se vuelva a unificar el país. Probablemente, los archivos sacerdotales cumplieron la función de conservar modelos intactos del Reino Medio que permitieron la recuperación de esta ilustración en el Reino Nuevo.

Transcurren algo menos de cuatrocientos años y la imagen del Campo de Hotep reaparece en Tebas, durante el reinado de Hatshepsut, en la sepultura de uno de sus colaboradores: Senenmut (TT 353). Esta tumba es el lugar más antiguo donde se documenta la viñeta 110 representándose como una imagen completamente estandarizada, con todas las escenas y textos que formarán parte de esta imagen durante el periodo de uso del LdSD.

La conexión establecida entre la viñeta de Senenmut y el plano 466 de el-Bersha nos ha permitido establecer que un duplicado del Plano venido de el-Bersha $(\gamma)$ sirvió como modelo para la realización de la primera copia maestra de la viñeta $110(\delta)$.

Las similitudes entre las viñetas de tipo A representadas sobre papiros y tumbas de este período por una parte y la de Senenmut por otra hace que consideremos que: a) esta última forma parte del tipo A; b) la copia maestra de la que derivó la utilizada para esta tumba $(\varepsilon)$ también fue modelo de copia para la representación del Campo de Juncos sobre papiro y tumbas de la Dinastía XVIII $(\zeta, \eta, \theta)$. 
Nuestro objetivo con este estudio iconográfico y con el establecimiento del stemma es remontarnos al denominado "arquetipo" que sería la versión de viñeta del Campo de Juncos que más se acerca a la original, es decir, a la primera copia maestra.

Aunque podemos afirmar que la viñeta 110 se basa en el plano de Hotep las diferencias entre los tipo A en algunas de sus escenas nos crean dudas a la hora de establecer "iconográficamente" cómo pudo haber sido el primer modelo de representación de esta región del Más Allá.

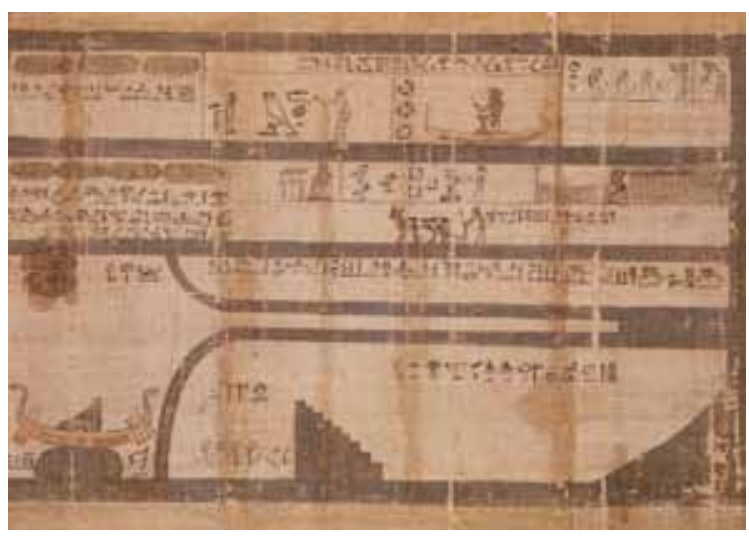

Figura 7. Papiro Leiden T6 (Dinastía XXI)

La viñeta 110 del papiro Leiden $\mathrm{T}^{33}$ (figura 7) nos permite sugerir cuál pudo ser el modelo más cercano al arquetipo. Este papiro pertenece [60 ] a hr-m-3h-byt y está datado entre finales de la Dinastía XXI y principios de la Dinastía XXII. Si atendemos a la estructura de su viñeta podemos apreciar cómo la disposición de los elementos jeroglíficos del primer y segundo registro son idénticos a los de Senenmut, de tal manera que la imagen del Campo de este papiro parece una réplica de la de la tumba. El hecho de que este papiro, datado unos cuatrocientos años después de nuestra identificación del tipo A en la Dinastía XVIII, sea el más parecido iconográficamente a la tumba de Senenmut implica que la primera viñeta 110 , que se creó probablemente en primer lugar para servir de modelo a la TT 353, no fue exclusivo para esta tumba sino que la copia maestra debió de permanecer en un taller para ser reproducida en otros papiros ${ }^{34}$. Esto posibilitó la recuperación de este modelo durante la Dinastía XXI.

El hecho de la que la viñeta 110 de $h r-m-3 h$ - byt sea una réplica de Senenmut, pero no reproduzca las escenas de éste bebiendo del canal, puede ser la clave para hipotetizar cómo pudo haber sido la primera representación del Campo de Juncos. Si el escriba de la Dinastía XXI reprodujo la copia maestra tenía que haber dibujado las escenas del difunto bebiendo agua, el hecho de que no lo haga probablemente indique que éstas no se hallaban sino que fueron un añadido del escriba que dibujó la imagen en la tumba de Senenmut en un intento de individualizarla. Esto explicaría también el hecho de que no aparezcan representadas en las otras viñetas que reproducen el tipo A, tanto en tumbas como en papiros, las cuales también tienen una serie de características que parecen individualizarlas:

a) El papiro de Userhat, en el primer registro, convierte la escena del difunto delante de la figura momiforme en una escena de apertura de boca.

b) En el papiro de Iuia podemos ver la introducción de la escena de lino en el primer registro además de la incorporación de su mujer.

33. Quiero agradecer al Dr. Maarten Raven del Museo de Leiden el envío de este papiro fundamental en esta investigación.

34. Curiosamente ninguno de los papiros documentados de la dinastía XVIII la reproducen o bien éstos se han perdido. Durante la Dinastía XIX no la documentamos tampoco y es sólo durante la Dinastía XXI cuando se produce una búsqueda por parte de los escribas de este periodo de modelos anteriores cuando aparece. 

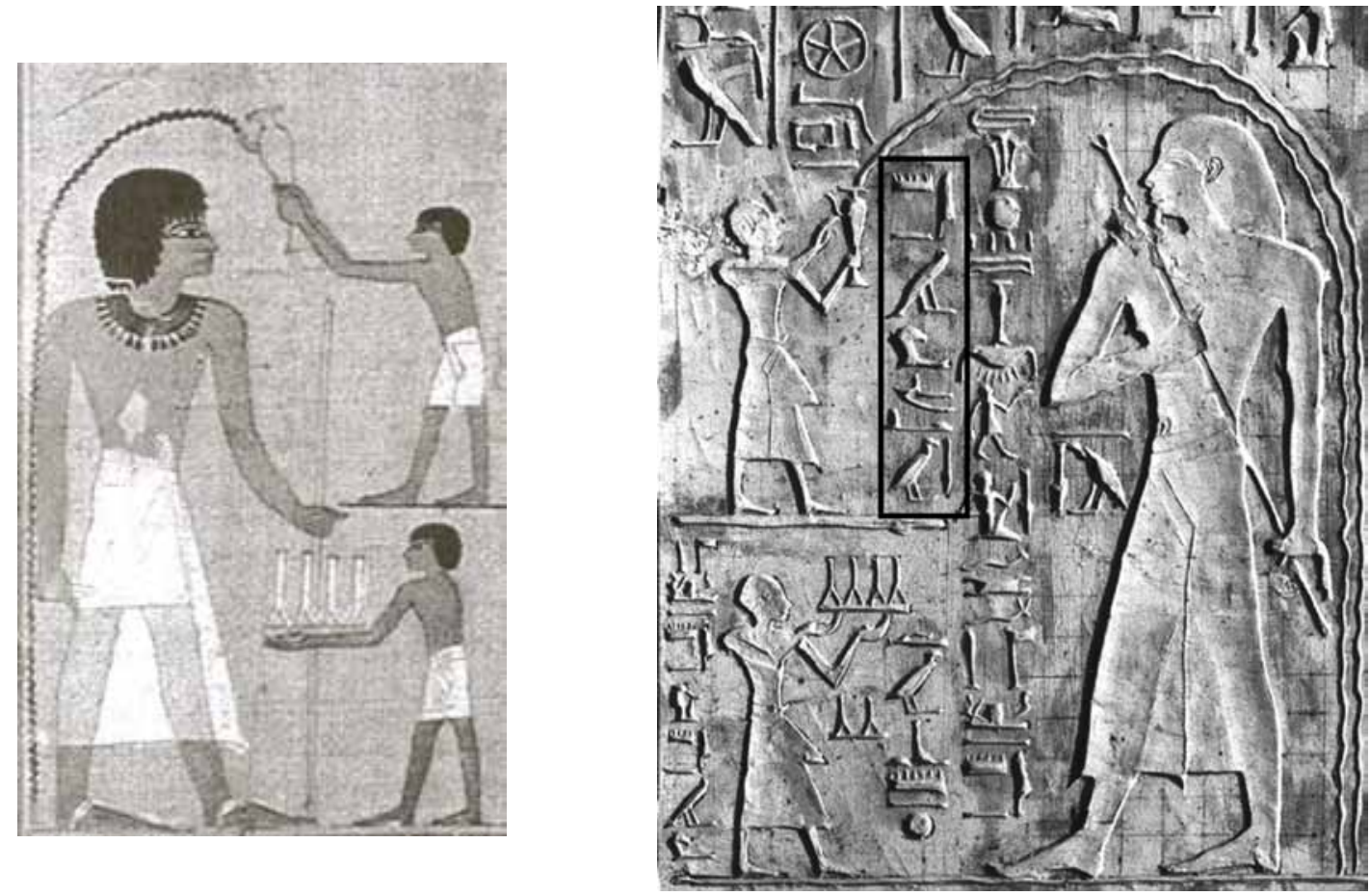

Figura 8. Escena de purificación anexa a las viñetas tipo A en el papiro de Userhat (izquierda) y en la tumba de Senenmut (derecha), la única que tiene un oferente identificado (véase también figura 4)

c) El papiro de Nebseni introduce variaciones textuales en el tercer registro como son la denominación de los cuatro dioses:

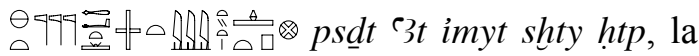
Gran Eneada que está en los dos Campos de Ofrenda o la identificación del desvío del canal sobre el que se coloca la barca como A

d) En el papiro de Neferubenef, en el segundo registro, el difunto aparece sentado delante de una relación de signos que indican diferentes ofrendas.

Todas estas diferencias nos indican que el hecho de que exista un solo tipo en este periodo no tiene por qué suponer una reproducción exacta de la copia maestra, la cual parece actuar como base. También el hecho de que estos cambios indicados sean significativos en su contenido podría sugerir que los escribas de este periodo, a la hora de reproducir las ilustraciones del LdSD, tenían libertad en la "reinterpretación" de la copia maestra.

La característica más singular de la tipo A se corresponde a la escena de libación y ofrenda de telas adjunta a todas las viñetas. En Senenmut el oferente que aparece representado dos veces en este acto ritual es su hermano Amenemhat (figura 8). En el resto de los papiros tipo A, no hay una identificación de este personaje lo que significaría que quien cumple el ritual de ofrenda puede ser cualquiera ${ }^{35}$. Aunque este dato podría parecer concluyente para considerar que la primera copia maestra de la viñeta 110 fue

35. Estos dos personajes no aparecerán en ninguna viñeta posterior identificados. Sin embargo, sí los podemos encontrar caracterizados de tal manera que parezca que son dos individuos diferentes los que se hallan envueltos en esta escena ritual. Ver: papiro de Neferubenef (Louvre N. 3092) en: Ratié, 1968. 
realizada para la TT 353, también podríamos proponer otra posible interpretación: la copia maestra que sirvió a los modelos tipo A no tendría identificado a este personaje atribuyéndosele sólo un nombre en la tumba de Senenmut ${ }^{36}$. Esta hipótesis podría apoyarse en el hecho de que esta escena no fue creada para incorporarse a la viñeta ya que la encontramos formando parte de otros programas decorativos ${ }^{37}$. Una reproducción exacta del difunto recibiendo una libación y ofrenda de telas por parte de dos oferentes aparece en tumbas durante el Reino Nuevo ${ }^{38}$, lo que nos llevaría, por tanto, a hablar de una imagen arquetipo que sería utilizada para diferentes contextos.

Otras dos viñetas de tumbas (TT 57 y TTC4) ${ }^{39}$, de la zona de Gurna y con datación posterior a la época de Amenhotep III, las podemos identificar también con la tipología A. Estas representaciones coinciden en la orientación de sus elementos iconográficos con la tumba de Senenmut, lo que nos permite derivarlas de la copia maestra $(\delta)$. Sin embargo, una particularidad concreta, que tiene que ver con la introducción de un texto entre las dos islas del tercer registro, las separa de Senenmut y de la representación de la viñeta sobre papiros. El hecho de que este texto se reproduzca en las dos viñetas quiere decir que se basaron en una misma copia maestra $(\theta)$.

Si tenemos en cuenta que no se creó un nuevo modelo para las tumbas de este periodo podemos extraer dos conclusiones: primero, que probablemente el modelo tipo A fue el más popular en esta época en Tebas o quizás el único $\mathrm{y}$, segundo, que este único modelo fue utilizado tanto para su reproducción en papiro como en tumbas. Es importante destacar este aspecto ya que normalmente las representaciones posteriores de la viñeta en tumbas parecen ser más una reinterpretación de la imagen sobre los papiros que una reproducción exacta de ellos ${ }^{40}$.

Las diferencias y similitudes entre el grupo de papiros tipo A, especialmente en lo que en la estructura o marco general de la viñeta se refiere, nos ha permitido ver que probablemente debieron de existir dos copias maestras derivadas de $\delta$ para ser representadas sobre papiro: $\zeta$ y $\eta$.

Teniendo en cuenta que encontramos una única tipología de viñeta del Campo de Juncos en Tebas durante la Dinastía XVIII y que su número es bastante escaso, resulta original la cantidad de variaciones que se introdujeron en el interior de las imágenes en el proceso de reproducción de éstas.

Por último, el lugar de producción de los tipos A merece nuestra atención ya que, la procedencia menfita del papiro de Nebseni nos plantea un problema a la hora de establecer la transmisión de este modelo. Según las investigaciones del Libro de la Salida al Día sobre papiro, éste surgió en los talleres tebanos en la Dinastía XVIII.

Las características singulares de este papiro podrían plantear la posibilidad de una doble tradición en los inicios de este libro funerario.

36. Esto podría ponerse en relación con que Amenemhat aparece también representado en la falsa puerta.

37. La representación del difunto a gran tamaño servido por dos personajes a menor escala ya la encontramos desde el Primer Periodo Intermedio.

38. En la tumba de Aper-El en Saqqara y en la TT 165. Ver: Zivie, 1988: Planche 14 y Hartwing, 2004: 239.

39. TT 57, foto cedida por el Museo Metropolitano de Arte (Nueva York), TT C4, Manniche, 1988. Ver: http://www.thebanmappingproject.com.

40. Una excepción notable es la viñeta representada en la tumba de Osorkón II en Tanis, una representación muy similar a la del papiro de Greenfield, ver, Budge, 1912. En la Dinastía XIX-XX aparecen nuevos modelos de viñetas en las tumbas. 
Si atendemos al diseño general del papiro, es el único de los ejemplares que está dibujado con trazos negros y que presenta una estructura y disposición de viñetas particular que lo diferencian del resto de papiros. Sin embargo, el establecimiento del modelo tipo A del Campo de Juncos y la inclusión del papiro de Nebseni dentro de este grupo, denota un modelo común y nos permite afirmar que este ejemplar menfita salió probablemente de un taller tebano al igual que el resto de papiros tipo A. Otro motivo que nos llevaría a establecer su procedencia tebana es la similitud de la estructura de la viñeta con la de la tumba de Senenmut, nuestro modelo más antiguo y aspecto que también comparte con la viñeta de Neferubenef de origen tebano.

La relación de estas dos ciudades en este periodo (Menfis era la capital administrativa de Egipto y Tebas la religiosa) nos permite plantear la hipótesis de que el papiro de Nebseni fue fabricado en los talleres tebanos y pudo partir de esta ciudad a Menfis para formar parte del ajuar funerario de este individuo o una copia del modelo $(\zeta)$ fue trasladada a un taller menfita para ser reproducida ${ }^{41}$. En todo caso tendríamos que hablar de un único lugar de producción del modelo original de la viñeta del Campo de Juncos, que sería Tebas. decorar las tumbas de otras regiones, como por ejemplo, la de los reyes de Tanis. Ver: Lull, 2002. 


\section{Bibliografía}

Álvarez Sosa, M.

en prensa The vignette of chapter 110 as a means of understanding the Book of Going Forth by Day during the $21^{\text {st }}$ Dynasty en Kousoulis, P. (ed.): $X^{\text {th }}$ International Congress of Egyptologists, Leuven.

Belmonte, J.A; Shaltout, M.

2007 The Astronomical Ceiling of Senenmut: a Dream of Mystery and Imagination en Zedda, M. y Belmonte, J.A. (ed.): Light and Shadows in Cultural Astronomy. Proceedings of the SEAC 2005, Isili, Italy, Dolianova: 145-154.

BuCK, A. DE

1935-1961 The Egyptian Coffin Texts. Chicago.

Budge, E.A.W.

1912 The Greenfield Papyrus in the British Museum. London.

Cerny, J.

1952 Paper \& Books in Ancient Egypt. London.

DORMAN, P.

1991 The Tombs of Senenmut. The Architecture and Decoration of Tombs 71 and 353. New York.

FAULKNER, R. O.

1969 The Ancient Egyptian Pyramid Texts. Warminster.

[64] 1978 The Ancient Egyptian Coffin Texts. Warminster, 3 vols.

1988 A Concise Dictionary of Middle Egyptian. Oxford.

HAYS, H. M.

2004 Transformation of Context: The Field of Rushes in Old and Middle Kingdom Mortuary Literature, en Bickel, S. y Mathieu, B. (eds.): D'un monde à l'autre. Textes des pyramides et Textes des sarcophages. Actes de la table ronde internationale: Textes des Pyramides versus Textes des Sarcophages, Le Caire: 175-200.

HaRTwig, M.

2004 Tomb Painting and Identity in Ancient Thebes, 1419-1372 BCE. (Monumenta Aegyptiaca X, Serie Imago 2). Turnhout, Belgium.

LAPP, G.

2003 The Papyrus of Nebseny (BM EA 9900). (Catalogue of the Books of the Dead in the British Museum 3). London.

LEPSIUS, R.

1842 Das Todtenbuch der Ägypter. Leipzig.

LESKO, L. H.

1971/1972 The Field of Hetep in Egyptian Coffin Texts, JARCE 9: 89-101.

1977 The ancient Egyptian Book of Two Ways. Berkeley.

LUCARELLI, R.

2006 Book of the Dead of Gatseshen. Ancient Egyptian funerary religion of the $10^{\text {th }}$ century B.C. Leiden.

LuLL, J.

2002 Las tumbas reales egipcias del Tercer Periodo Intermedio, Dinastías XXI-XXV: tradición y cambios. Oxford.

Lull, J.; Belmonte, J.A.

2006 A firmament above Thebes: Uncovering the Constellations of Ancient Egyptians, JHA XXXVII: 373-392.

MANNICHE, L.

1988 Lost tombs. A study of certain $18^{\text {th }}$ dynasty monuments in the theban necropolis. London. 
Moreno García, J.C.

1999 Hwt et le milieu rural égyptien du IIIe millénaire : économie, administration et organisation territoriale. Paris.

MunRo, I.

1987 Untersuchungen zu den Totenbuch-Papyri der18. Dynastie. London.

1994 Die Totenbuch-Handschriften der 18 Dynastie in Ägyptischen Museum Cairo. Wiesbaden.

2001 Das Totenbuch des Pa-en-nesti-taui aus der Regierungszeit des Amenemope (pLondon $B M$ 10064). Wiesbaden.

Neugebauer, O; Parker, R.

1960-1969 Ancient Astronomical Texts. Providence, 3 vols.

Niwinski, A.

1989 Studies on the illustrated Theban funerary papyri of the $11^{\text {th }}$ and $10^{\text {th }}$ centuries B.C. (OBO 86). Göttingen.

Pogo, A.

1930 The astronomical ceiling decoration in the tomb of Senmut, Isis 14: 301-25.
Porter, B; Moss, R.B; Malek, J.

1985 Topographical Bibliography of Ancient Egyptian Hieroglyphic Texts, Statues, Reliefs and Paintings I.1. Theban Necropolis. Private Tombs. Oxford.

RATiÉ, S.

1968 Lepapyrus de Neferoubenef(LouvreIII93). (BdE 43). Le Caire.

Saleh, M.

1975 Das Totenbuch in den Thebanischen Beamtengräbern des Neuen Reiches. Texte und Vignetten. Mainz am Rhein.

WiLlems, H.

1988 Chests of Life. A Study of the Typology and Development of Middle Kingdom Standard Class Coffins. Leiden.

ZIVIE, A.

1988 Memphis et ses nécropoles au Nouvel Empire. Paris. 


\section{Trabajos de Egiptología Papers on Ancient Egypt}

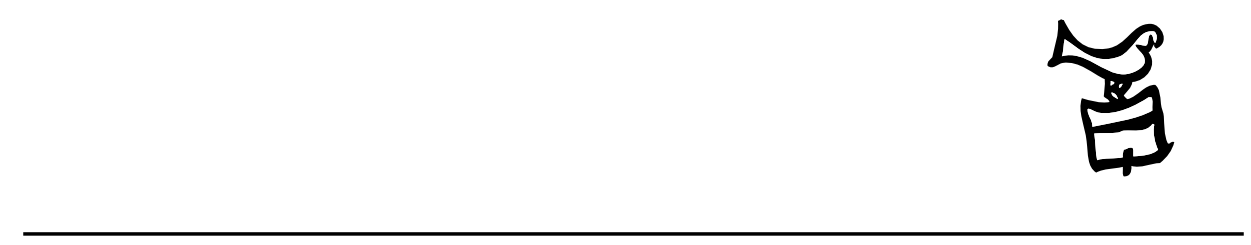

Número 5/1 2009 


\section{Actas \\ III Congreso Ibérico de Egiptología III Congresso Ibérico de Egiptologia}

Editores

Miguel Ángel Molinero Polo Covadonga Sevilla Cueva 


\title{
Editor
}

Miguel Ángel Molinero Polo

Universidad de La Laguna

\section{Consejo Editorial}

\author{
Antonio Pérez Largacha \\ Universidad de Castilla-La Mancha \\ José-R. Pérez-Accino \\ Birkbeck, Universidad de Londres \\ Covadonga Sevilla Cueva \\ Universidad Autónoma de Madrid
}

\section{Comité Científico}

Josep Cervelló i Autuori

Universitat Autònoma de Barcelona

$\mathrm{M}^{\mathrm{a}}$ José lópez Grande

Universidad Autónoma de Madrid

Josep Padró i Parcerisa

Universitat de Barcelona

$\mathrm{M}^{\mathrm{a}}$ Carmen Pérez Die

Museo Arqueológico Nacional, Madrid

Ester Pons Mellado

Museo Arqueológico Nacional, Madrid

José M. Serrano Delgado

Universidad de Sevilla

\section{Colaboradores Editoriales}

Linda Steynor

English editorial assistant

Hervé Mouriacoux

Assistant éditorial pour la langue française 
Trabajos de Egiptología está producida por Isfet. Egiptología e Historia c/ Blanco $1,2^{\circ}$

38400 Puerto de la Cruz

Tenerife-Islas Canarias

España

Maquetación: Proyecto Limón

(C) Autores de los artículos aparecidos

y Consejo Editorial de Trabajos de Egiptología - Papers on ancient Egypt

Depósito Legal: TF-2302-2009

ISSN: $1695-4750$

Imprime: Gráfica Los Majuelos, S.L.L.

imprenta@graficaslosmajuelos.com

Tfno.: 922311455 


\section{Comité Científico \\ III Congreso Ibérico de Egiptología III Congresso Ibérico de Egiptologia}

Miguel Á. Molinero Polo

Universidad de La Laguna

Presidente del Comité Organizador del III Congreso Ibérico de Egiptología

Miembro del Comité Organizador del I Encuentro de Egiptología

Josep Cervelló Autuori

Universitat Autònoma de Barcelona

Presidente del Comité Organizador del II Congreso Ibérico de Egiptologia

José Manuel Galán Allué

Consejo Superior de Investigaciones Cientificas

Director del Proyecto Djehuty, Luxor, Egipto

$\mathrm{M}^{\mathrm{a}}$ Helena Trindade Lopes

Universidad de Lisboa

Directora de la Misión Arqueológica Portuguesa en Menfis

Josep Padró i Parcerisa

Universitat de Barcelona

Director de la Misión Arqueológica de Oxirrinco

Antonio Pérez Largacha

Universidad de Castilla - La Mancha

Miembro del Comité Organizador del I Encuentro de Egiptología

José Ramón Pérez-Accino

Birkbeck College, University of London

Miembro del Comité Organizador del I Encuentro de Egiptología

$\mathrm{M}^{\mathrm{a}}$. Carmen Pérez Díe

Museo Arqueológico Nacional

Directora de la Misión Arqueológica Española en Heracleópolis Magna, Egipto

Covadonga Sevilla Cueva

Universidad Autónoma de Madrid

Miembro del Comité Organizador del I Encuentro de Egiptología 